\title{
Los repartimientos reales: el caso de Chucuito (Perú) en el siglo XVI
}

\author{
Héctor Omar Noejovich \\ Pontificia Universidad Católica del Perú \\ hnoejov@macareo.pucp.edu.pe \\ Estela Cristina Salles \\ Universidad Nacional de Luján, Argentina \\ salles@generalrodriguez.com
}

\begin{abstract}
Resumen $^{1}$
En este artículo se hace un análisis de las encomiendas en cabeza de la corona en la provincia de Chucuito (Perú), antiguo asentamiento del reino Lupaqa, espacio que jamás tuvo encomendero alguno. Por esa razón la tributación en productos y servicios, característica de las encomiendas pretoledanas, no tuvo lugar en ese distrito, desarrollando una estrategia de supervivencia diferente, frente a la tributación y a los curas doctrineros. Un elemento esencial en este análisis es la posición geográfica y el hábitat, con sus recursos y su carácter prehispánico, al mismo tiempo que la evolución de la relación entre los repartimientos y la corona.

Palabras clave: ENCOMIENDA, REPARTIMIENTOS, CORONA ESPAÑOLA, PERU, CHUCUITO, SIGLO XVI.
\end{abstract}

\begin{abstract}
This article analyzes the crown encomiendas in the province of Chucuito (Perú), a prior settlement of the kingdom of Lupaqa,a space that never had an encomendero. Consequently, the tribute in goods and services that is characteristic of pre-Toledan encomiendas, did not take place in this district, which generated a different survival strategy for facing tribute and missionary priests. An essential elemnt in this analysis is geographic location and environment, with its resources and prehispanic characteristics, as well as the evolving relationship between repartimientos and the crown.
\end{abstract}

1 Una versión preliminar de este artículo fue presentada como ponencia en las III Jornadas Agrarias y Agroindustriales, Facultad de Ciencias Económicas, Universidad Nacional de Buenos Aires, Argentina, en noviembre de 2004, bajo el título "Una unidad de producción agrícola ganadera prehispánica convertida en generadora de renta colonial: el caso de Chucuito”. 
Key words: ENCOMIENDA, REPARTIMIENTOS, SPANISH CROWN, PERU, $16^{\mathrm{TH}}$ CENTURY.

\section{Introducción}

Ha sido frecuente en la historiografía latinoamericana considerar la encomienda como antecedente de la hacienda. Aun cuando esta idea es controversial², lo cierto es que la transformación de la "propiedad” y, más profundamente, las modificaciones en la organización de la producción, consecuencia de la intrusión española en la economía prehispánica, perfilaron una estructura agraria rentística, que se esparció durante varios siglos por el espacio latinoamericano ${ }^{3}$.

Como se sabe, la encomienda americana, que fue una forma de retribución para los conquistadores, era en esencia la cesión que les hacía la corona de su derecho a percibir tributos de los conquistados, teniendo aquellos, a su vez, la obligación del adoctrinamiento ${ }^{4}$. Formalmente no daba derecho a tierras 5 , pero en la práctica los encomenderos también obtenían mercedes de tierra, y, por tanto, una forma de explotarlas era dar trabajo a los indios para que les pagaran el tributo. Pero hubo casos en que tributaban directamente a la corona ${ }^{6}$, dando lugar a una articulación distinta de la existente entre la población indígena y los encomenderos.

En efecto, en los repartimientos asignados originariamente ${ }^{7}$ a la corona, ni la tributación ni el adoctrinamiento tuvieron intermediación y, por consiguiente, las estrategias de la

2 Para visiones contrapuestas véase: Manuel Burga, De la encomienda a la hacienda capitalista (Lima: IEP, 1976), para el caso del Perú; y Mario Góngora, Estancieros y encomenderos (Santiago de Chile, 1970) y El origen de los inquilinos de Chile central (Santiago de Chile: Icira, 1974), para el caso de Chile, como uno de los tantos ejemplos existentes en la historiografía sobre el tema.

3 Héctor Omar Noejovich, "El régimen de bienes en la América precolombina y el hecho colonial" Cisepa (Lima), 107 (1992), y Los albores de la economía americana (Lima: Pontificia Universidad Católica del Perú, 1996).

4 Esta también es una suerte de cesión de una obligación real, dado que la corona, de conformidad con las bulas papales, tenía derecho de conquista (ahí se fundamentaba su derecho al tributo) pero también obligación de predicamento (de ahí el adoctrinamiento).

5 A diferencia de las españolas, que daban derecho a tierras. Ruggiero Romano, Consideraciones (Lima: Fomciencias, 1992).

6 Según Teodoro Hampe, “La encomienda en el siglo XVI: estudio socioeconómico de una institución colonial” (memoria inédita, Lima, Pontificia Universidad Católica del Perú, 1983), 28: “[...] consta que el reino Lupaqa (con sede capital en Chucuito), el valle de Chincha y la isla de Puná fueron las primeras encomiendas adjudicadas directamente al rey, también se conoce que ciertos grupos indígenas, situados en Lima, Huánuco y Trujillo pertenecieron al estado [...]”.

7 Deseamos marcar la diferencia con aquellos repartimientos que originariamente estaban asignados a encomenderos y que luego, al quedar vacantes, revertieron a la corona. Aquí el proceso es distinto, pero su análisis escapa al objeto de este trabajo. 
población indígena, que tuvo relación directa tanto con los funcionarios reales como con los religiosos, fueron diferentes, tal como se verá en el desarrollo de este trabajo.

El caso que trataremos es el de la provincia de Chucuito, ex asentamiento del reino Lupaqa $^{8}$, espacio que jamás tuvo encomendero alguno, dado que desde sus comienzos fue un repartimiento en "cabeza de Su Majestad". Por esa razón, la tributación en productos y servicios, característica de las encomiendas pretoledanas, no tuvo lugar en ese distrito ${ }^{10} \mathrm{y}$, en consecuencia, desarrolló una estrategia de supervivencia distinta ${ }^{11}$ frente a la tributación y a los curas doctrineros, en relación con las encomiendas de los conquistadores.

Asimismo, es esencial tener presente la posición geográfica ${ }^{12}$ y el hábitat, con sus recursos y su carácter prehispánico, al mismo tiempo que la evolución de la relación entre el repartimiento y la corona. Igualmente, no hay que olvidar que la población del altiplano se caracterizaba por la actividad ganadera de sus habitantes, principalmente, la misma que se extendía, para completar su alimentación, a otros espacios ecológicos, pero manteniendo el control y la integración social por las redes de parentesco ${ }^{13}$. La ganadería, tal como la percibieron los visitadores de Toledo, fue la principal fuente de riqueza, según los conceptos españoles ${ }^{14}$. Eso marcó una diferencia notable con la formación de la propiedad rural en otras áreas, y, por ello, merece considerarse al reino Lupaqa como el primer país agrícola-ganadero de América.

8 Etnia aymara que aparece en los documentos en un plano dominante frente a los uros, habitantes del lago Titicaca.

9 Estela Cristina Salles, “La evolución tributaria de Chucuíto, sur del Perú, siglo XVI”, Journal of Iberian and Latin American Studies (Melbourne, Australia), (julio 2000); “Tributo y población en una encomienda real. Chucuito 1549-1574” (tesis, Universidad Nacional de Luján, Argentina, 2000) y "Cuestiones sobre Chucuito en el siglo XVI. Las exacciones de la Iglesia", en América bajo los Austrias, economía, cultura y sociedad, ed. Héctor Omar Noejovich (Lima: Pontificia Universidad Católica del Perú, 2001).

10 A excepción de una primera tasación de la Real Audiencia en 1553, que no tuvo efectos prácticos.

11 Estela Cristina Salles, "Martín Cari-Martín Cuxi. Dos estrategias disyuntivas de supervivencia frente al tributo" (actas de las V Jornadas Interescuelas de Departamentos de Historia y I Jornadas Rioplatenses de Historia, Montevideo, 1995); Héctor Omar Noejovich, "El pensamiento dual andino y sus implicaciones socioeconómicas”, Histórica (Lima), 19, num. 1 (1995); Los albores de la economía.

12 Véase Figura 1.

13 Las controlaban con sus mitmakunas, suerte de colonos de la misma etnia asentados en otras regiones, manteniendo los lazos de parentesco. Así, la provisión agrícola provenía del valle de Sama, en la vertiente occidental del altiplano, y del valle de Larecaja, en la vertiente oriental del mismo. Este modelo de organización, que aprovechaba "pisos ecológicos", ha sido tratado in extenso a partir de la obra de John V. Murra, El mundo andino. Población, medio ambiente y economía (Lima: IEP; Pontificia Universidad Católica del Perú, 2002).

14 Noejovich, Los albores, y "Las visitas de Chucuito en el siglo XVI: en torno a la visita secreta”, en El hombre y los Andes. Ensayos en honor a Franklin Pease G-Y (Lima: Pontificia Universidad Católica del Perú; Instituto Francés de Estudios Andinos; Banco de Crédito del Perú, 2002). 


\section{Figura 1 \\ Perú en el siglo XVI. Distancias según Garcí Díez de San Miguel (1567)}

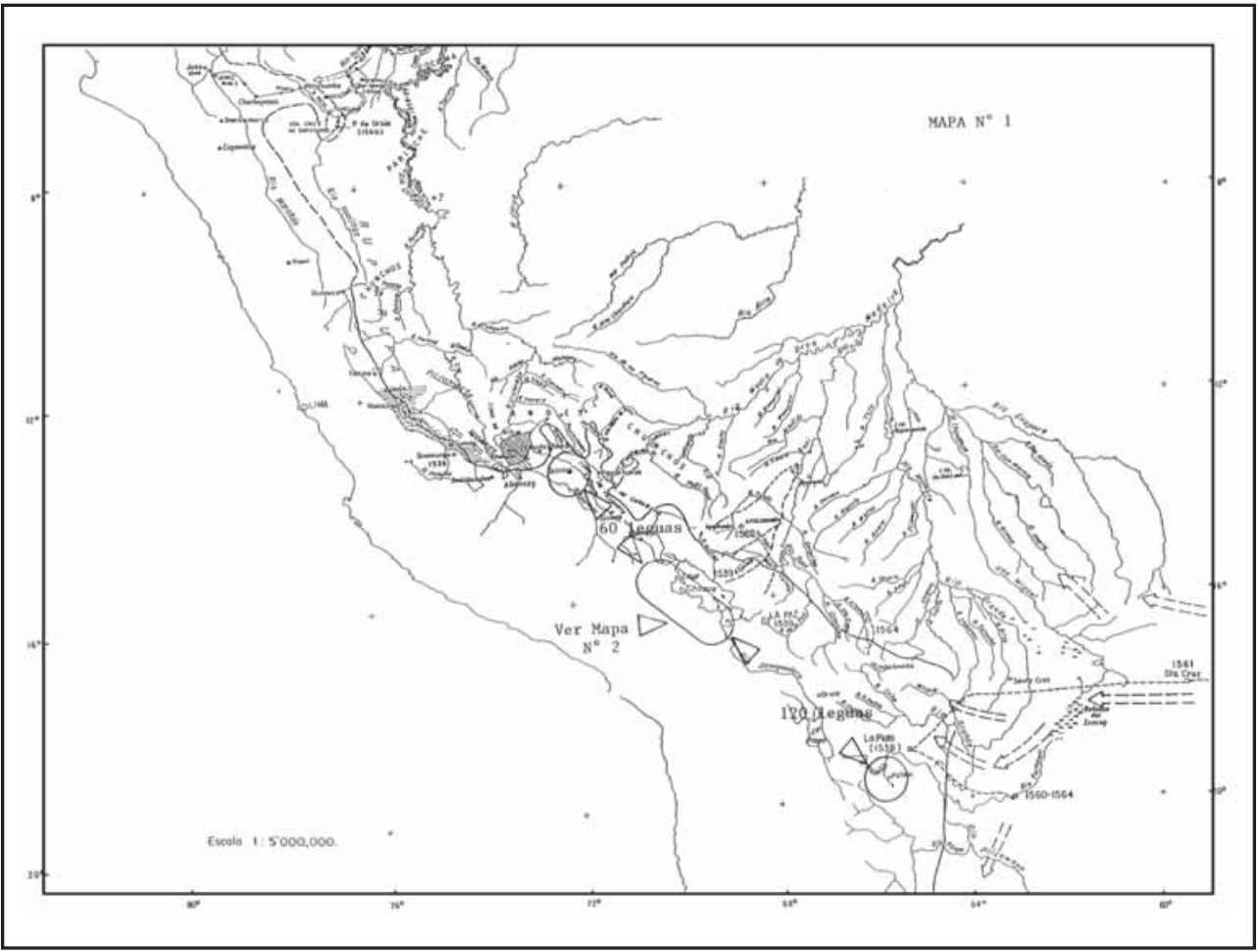

Fuente: Murra, El mundo andino, Población, medio ambiente y economía (Lima: IEP; Pontificia Universidad Católica del Perú, 2002) 82. 


\section{Figura 2 \\ La región de los lupaqa visitada por Garcí Díez de San Miguel (1567)}

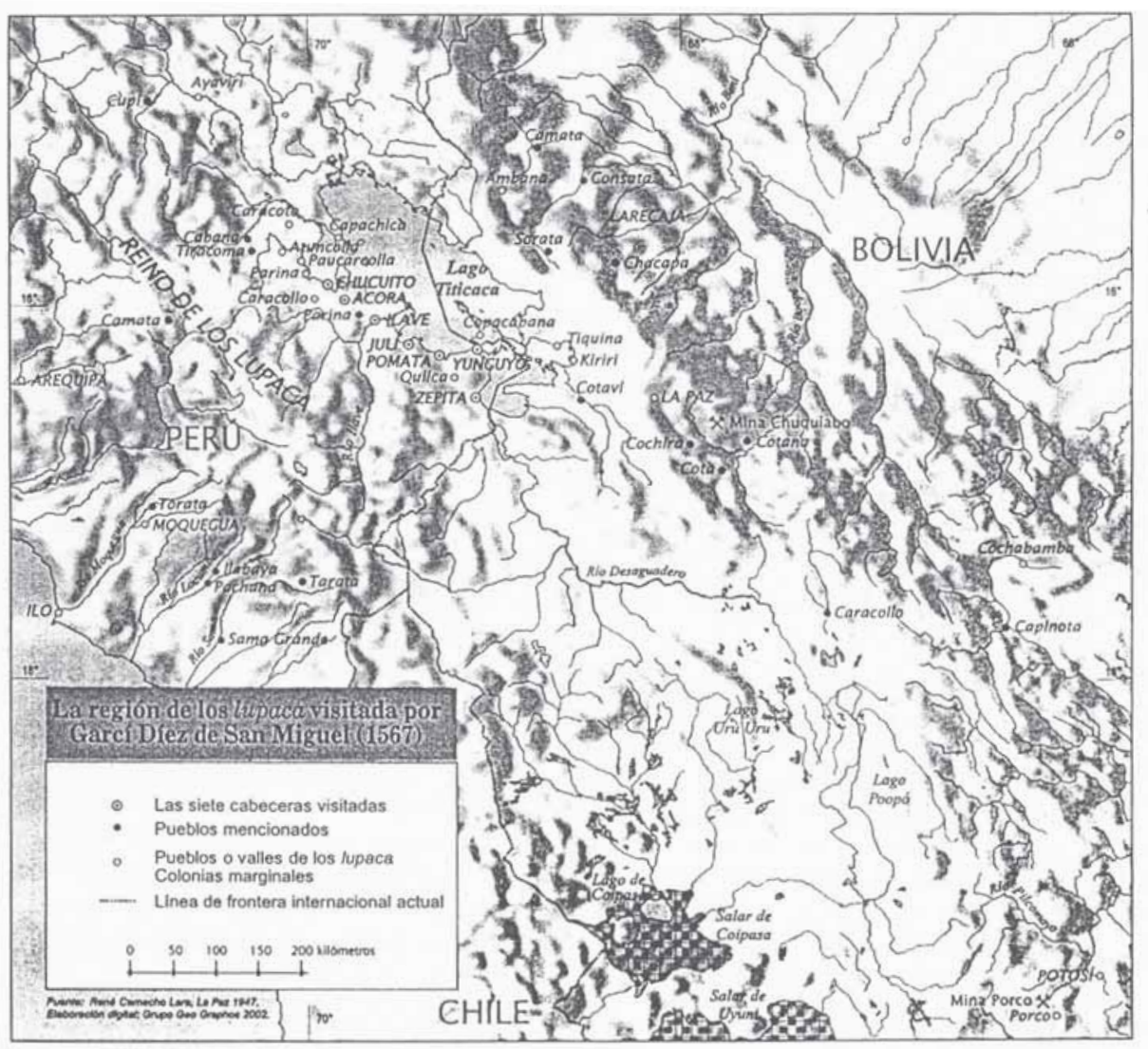

Fuente: Murra, El mundo andino, 193. 


\section{El hábitat: sus recursos y su posición prehispánica}

El espacio ocupado por el reino Lupaqa antes de la conquista española era la cuenca suroccidental del lago Titicaca ${ }^{15}$. En la época colonial la zona fue la provincia de Chucuito ${ }^{16}$, denominación que se conserva (aunque fue subdividida), y se encuentra actualmente en el departamento de Puno, aproximadamente en los $16^{\circ}$ de latitud sur y $70^{\circ}$ de longitud oeste ${ }^{17}$.

El asentamiento está localizado en la ribera suroccidental del lago Titicaca a una altitud de 3.800 a 3.900 msnm, en la parte más baja de la puna que la rodea, la cual supera los 4.000. La capital era el pueblo del mismo nombre y existían otros seis pueblos o cabeceras hacia el sur: Acora, Ilave (a orillas del río homónimo), Juli, Pomata, Yunguyo y Zepita, los mismos que subsisten hasta el presente. Estos dos últimos están ubicados a orillas de la laguna de Huinamarca, que se conecta con el lago Titicaca a través del estrecho de Tiquina.

La zona circunlacustre es apta para cierto tipo de agricultura y especialmente para el engorde de ganado. Sus precipitaciones pluviales son del orden de los $800 \mathrm{~mm}$ al año durante la estación de verano ${ }^{18}$. La temperatura media anual es de $8{ }^{\circ} \mathrm{C}$, con máximas de $14{ }^{\circ} \mathrm{C}$ y mínimas de $2{ }^{\circ} \mathrm{C}^{19}$. Antes de la Conquista esta provincia era conocida como el reino de los Lupaqas, un pueblo de habla aymara. El control de recursos complementarios para la alimentación se extendía a los valles de Sama, Moquegua y Lluta, que desembocan en el océano Pacífico ${ }^{20}$. También había mitmaqkuna lupaqas en la vertiente oriental del lago en la provincia de Larecaja ${ }^{21}$. El envío de mitmaqkuna a zonas más bajas correspondía a la estrategia de control de pisos ecológicos analizada por Murra ${ }^{22}$. Los productos obtenidos de allí eran, principalmente, algodón, maíz, coca y ají. La actividad agrícola en el altiplano estaba limitada a los tubérculos, y la pecuaria, a la cría de camélidos, tanto para carne (charqui) como para lana: de allí la importancia del tejido, como forma de utilizar los rebaños ${ }^{23}$. El altiplano no es muy

15 Véase Figura 2.

16 El Perú tiene un régimen unitario. Se divide en departamentos (a cargo de un prefecto nombrado desde Lima), provincias y distritos. Estos dos últimos tienen alcaldes (provinciales y distritales) elegidos por votación popular.

17 Salles, “Tributo y población”.

18 Aproximadamente 130 días al año.

19 Santiago Antunez de Mayolo, comp., Geografía del Perú. Anuario geográfico departamental (Lima: Sociedad Geográfica, 1990), libro 21, opúsculo 24.21a.

20 “[...] y Moquegua que es un pueblo donde hay indios de toda la provincia y que en el pueblo de Sama hay indios de toda esta provincia y que en el pueblo que se dice de Larecaja hay indios de este pueblo y de toda la provincia y que en el pueblo de Capinota hay muchos indios de toda la provincia [....]". Garcí Díez de San Miguel, Visita a la provincia de Chucuito de 1567, ed. Waldemar Espinoza Soriano ([1567]; Lima: Casa de la Cultura, 1964), 14. 
apropiado para la agricultura, aunque los lupaqa habían obtenido la aclimatación de cultivos resistentes a las heladas, como la papa, y disponían de técnicas de almacenamiento, como el caso del chuñu. Por otra parte, es importante tener en cuenta que en los Andes hay tres regiones: la Puna (arriba de $3.500 \mathrm{msnm}$ ), la Quechua (entre 2.000 y $3.500 \mathrm{msnm}$ ) y la Yunga debajo de los $2.000 \mathrm{msnm}^{25}$ a distancias relativamente cortas ${ }^{24}$. En este caso particular, el centro principal estaba radicado en la Puna, a diferencia de otros centros políticos como Cuzco, Huanta, Huánuco, que estaban situados en la Quechua.

Un estudio contemporáneo de una hacienda puneña nos da una idea más clara del ecosistema de la región ${ }^{26}$ :

En las haciendas de Puno, así como en todas las de la sierra peruana, dedicadas a la ganadería extensiva, la inmensa mayoría de la extensión está cubierta de pastos naturales y muy poca de pastos cultivados. Estos pastos naturales son de varias especies y el más extendido es el “icchu”. Es una gramínea que es de relativo valor nutritivo, muy especialmente cuando está seco. Este pasto es muy resistente a las heladas y sequía, generalmente crece de los 2.000 hasta altitudes próximas a los 5.000 metros sobre el nivel del mar. Su rendimiento y calidad va disminuyendo con la altitud. Además del "icchu” hay otros pastos naturales, que crecen entremezclados con este y que son menos comunes, pero de mayor valor nutritivo ${ }^{27}$.

Y como señala el mismo autor acerca de la diferencia en la dependencia de recursos:

En la región de Puno, las haciendas tienen dependencia diferente en la agricultura y en la ganadería. La agricultura no tiene seguridad, es decir que depende definitivamente de factores fuera del control humano, tal como es el clima, lluvia, etc. [...].

En el caso de la ganadería, sea la cría de ovinos o alpacas, el factor climatérico se hace sentir pero no causa los graves estragos que produce en la agricultura [...].

21 Thierry Saignes, Algunas hipótesis acerca del control aymara de los valles de Larecaja (La Paz, 1975); “Les ethnies dans les vallées de Larecaja: de la filiation a la résidence”, Annales (París), 33, núm. 5/6 (1975), y "Les Lupacas dans les vallées orientales des Andes: trajets spatiaux et repères démographiques: XVI-XVII siècles”, Mélanges de la Casa de Vélasquez (París), 17 (1981): 147-182.

22 Murra, El mundo andino, 83, 142.

23 Ibídem, 308, 327.

24 Olivier Dollfus, El reto del espacio andino (Lima: IEP, 1981).

25 Por ejemplo, saliendo de Lima hacia el oriente, en $135 \mathrm{~km}$ se alcanzan los $4.765 \mathrm{msnm}$.

26 Preparado como consecuencia de la Ley de Reforma Agraria promulgada el 24 de junio de 1969 para todo el territorio peruano.

27 Luis Deustua Jameson, Organización de una hacienda ganadera en Puno, Informe 28 (Lima: Ministerio de Agricultura; Coama, 1972), 3. 
En resumen, la sierra de Puno es una región ganadera (ovinos, alpacas), donde la agricultura es una empresa de segundo orden destinada al autoabastecimiento de ciertos productos agrícolas (papas, cebada, avena, trigo) ${ }^{28}$.

Podemos afirmar que la situación geográfica de la altiplanicie del Collao, y del Titicaca en particular, entre las cordilleras oriental y occidental, en el camino de Cuzco a Potosí, hizo del reino Lupaqa un punto estratégico, respecto de la circulación de trabajo y de productos. También lo fue en tiempos prehispánicos, especialmente para la colonización del valle de Cochabamba realizada por Huayna Capac ${ }^{29}$. Adicionalmente, Meiklejohn postula como hipótesis una suerte de alianza entre la élite cuzqueña y los lupaqa, evidenciada por el grado de autonomía de que gozaban estos últimos ${ }^{30}$.

En el siglo XVI la provincia de Chucuito estaba constituida por los siete pueblos o cabeceras señalados anteriormente; Chucuito era la sede de la élite político-cultural provincial. Durante las visitas de Garcí Diez de San Miguel de 1567 y la general de Toledo de 1574, Martín Cari y Martín Cuxi eran los kurakakuna ${ }^{31}$ o mallkus de la provincia. Excepto Juli, que seguía al modelo tripartito Hanan-Urin-Ayantas, el resto de las cabeceras respondían al sistema de bipartición Hanan-Urin.

La provincia estaba habitada principalmente por dos grupos étnicos: los aymara y los uros. Los primeros, que constituían la mayoría poblacional, tenían acceso a casi todos los recursos. El grupo minoritario era el de los uros, que habitaba la zona lacustre y se dedicaba a actividades relacionadas con el control de los recursos facilitados por el hábitat del gran lago.

Como lo confirma la visión contemporánea de la zona, la región necesariamente dependía del denominado "archipiélago vertical" para un mayor control de los pisos ecológicos ${ }^{32}$, a fin de complementar su subsistencia. Los mitmaqkuna de la provincia de Chucuito cumplían con esa función de complementariedad ecológica, la cual se traducía en una estrategia de obtención de todos los recursos para alcanzar la subsistencia en los valles occidentales de Moquegua, Sama y Lluta y en los orientales de Larecaja, como mencionamos anteriormente.

En la visita de Garcí Diez de San Miguel se observa la inexistencia del concepto de territorialidad en las sayas para esa época (1567); en muchas oportunidades se com-

28 Ibídem, 6-7.

29 Alfonso Morales, ed., Repartimiento de tierra por el Inca Huayna Capac: testimonio de un documento de 1556 ([1556]; Cochabamba, Perú: Universidad Mayor de San Simón, 1977), y Nathan Wachtel, "Les mitmas de la vallée de Cochabamba: la politique de colonisation de Huayna Capac", Journal de las Société des Américanistes (París), 67 (1982).

30 Norman Meiklejohn, La Iglesia y los Lupaqas (Lima, 1988).

31 Usaremos indistintamente el vocablo quechua kurakakuna, plural de kuraka, el de mallku, de origen aymara y el de "cacique”, de origen caribeño, introducido por los españoles en Suramérica.

32 Murra, El mundo andino, 83 y 132. 
probó, en diversas visitas del siglo XVI, que podían convivir miembros de distintas mitades en un mismo espacio geográfico. La etnohistoria andina conceptúa este modelo como patrón disperso de asentamiento o espacio discontinuo; discontinuidad de áreas nucleares ${ }^{33}$ o también como espacio salpicado, postulada por Rostworowski ${ }^{34}$. Es evidente que la noción de espacio y territorialidad de los europeos en esa época y la que nosotros manejamos en la actualidad son muy diferentes a la del mundo andino que estamos analizando en esta oportunidad ${ }^{35}$.

En síntesis, los lupaqa fueron, al parecer, una entidad autónoma dentro del Tawantinsuyu, aún cuando estaban bajo su control desde mediados del siglo XV. Se

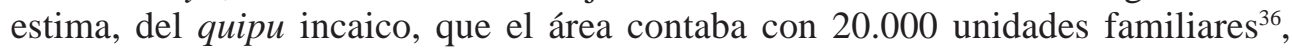
aproximadamente, abarcando el área nuclear desde Chucuito hasta el río Desaguade$\mathrm{ro}^{37}$. Poseía enclaves en las vertientes orientales y occidentales de los Andes donde se producía coca y maíz, ya que en la zona nuclear resultaba imposible hacerlo por estar a más de 3.800 metros de altitud.

\section{La evolución del repartimiento Chucuito}

Pizarro ocupa el Cuzco en 1534, refundando la ciudad, sobre los muros y construcciones incaicas, en un acto con carga simbólica. No obstante que en la capitulación de Toledo no hay reserva alguna de repartimientos a favor de la corona ${ }^{38}$, esta deseaba obtener repartimientos de indios en el área, pero el conquistador se asigna como encomendero de los repartimientos de Yucay, Angaraes, Pilcota, Naya y Vilca (distrito de Cuzco), con una renta de 11.500 pesos $^{39}$.

Sin embargo, a semejanza de lo ocurrido con Cortés en México (y anteriormente con Colón), la corona no era muy proclive a cumplir con sus compromisos, especialmente cuando observaba las riquezas que quedaban en manos de los conquistadores a través de las encomiendas ${ }^{40}$.

33 Franklin Pease, "Relaciones entre los grupos étnicos de la sierra del sur y la costa: continuidades y discontinuidades”, en El hombre y su ambiente en los Andes centrales, Serie Ethnological Studies, núm. 10, eds. Luis Millones y Hyrosayu Tomoeda (Osaka, 1982).

34 María Rostworowski, Estructuras andinas de poder (Lima: IEP, 1983).

35 “Para el caso andino, la ‘discontinuidad territorial’ es generalmente aceptada. El objetivo de las guerras y la expansión no era la conquista territorial sino, más bien, la extensión de la 'red de parentesco' y, consecuentemente, del poder ejercido a través de ella. El llamado 'Imperio de los Incas' -el Tawantinsuyu-, no lo era en el sentido de la Roma Imperial o del Imperio Carolingio. El ejercicio del poder no era esencialmente jurisdiccional”. Noejovich, Los albores, 442-443.

36 Díez, Visita.

37 John Hyslop, “El área Lupaqa bajo el dominio incaico”, Histórica (Lima), 3, núm. 1.

38 Ronald Escobedo, El tributo indígena en el Perú (siglos XVI-XVIII) (Pamplona: Universidad de Navarra, 1979), 138-139.

39 Ibídem, 142.

40 Estas, a diferencia de las españolas, no daban derecho a tierras, sino meramente a la percepción de tributos. Romano, Consideraciones, 67 y ss., y Noejovich, "Las visitas”, 211 y ss. 
En una real cédula de 1533, "La carta acordada sobre discreción ${ }^{41}$ de la tierra del Perú”, se señala:

[...] por qanto vistas las dichas informaciones con acuerdo y parecer de nuestro consejo y por voluntad que tenemos de hacer merced a los conquistadores e pobladores de la dicha tierra especialmente a los que tienen o tuvieren intención e voluntad de permanecer en ella tenemos acordado que se les haga repartimiento perpetuo de los dichos yndios tomando para nos y los reyes que después nos vinieren las cabeceras e provincias e pueblos que vosotros hallareis por la dicha información ser cumplideras a nuestro servicio y a nuestro estado y corona real y del restante $[. . .]^{42}$.

La historiografía invoca esta real cédula, fechada el 8 de marzo de 1533, como el origen del repartimiento de Chucuito "en cabeza de Su Majestad"43. Sin embargo, carecemos de información sobre la tributación del citado repartimiento entre 1533 y 1549. Por otro lado, el conflicto entre los encomenderos del Perú y la corona aparentemente era más antiguo que las Leyes Nuevas de 1542, que suprimieron el otorgamiento de nuevas encomiendas, ordenando que al fallecimiento de las existentes las mismas revertieran a la corona ${ }^{44}$. Por nuestra parte inferimos del texto citado que el conflicto en realidad nació de la “distribución” entre la corona y los encomenderos, con referencia al repartimiento de indios.

Tal como se señala en otros trabajos ${ }^{45}$, el obispo Berlanga fue comisionado en calidad de visitador para verificar el cumplimiento de la real cédula del 8 de marzo de 1533 . Comenzó sus funciones el 20 de agosto de $1535^{46}$; según los testigos se habían reservado para Su Majestad los repartimientos de los Reyes (Lima), Huánuco, Trujillo y el Collao, siendo imprecisos los datos respecto del Cuzco ${ }^{47}$. Como referencia está el testimonio de Hernando de Soto:

41 Debió ser “discrición”, correspondiente a “descripción”.

42 Tomando de Raúl Porras Barrenechea, Cedulario indiano (Lima, 1944), 127 y ss. Corresponde a AGN (Lima), leg. 565, libro 1, fojas 118 y ss.

43 Silvio Zavala, El servicio personal de los indios en el Perú, 1 t. (México: El Colegio de México, 1978); La encomienda indiana (México: Porrúa, 1992); Escobedo, El tributo, y Hampe, "La encomienda en el siglo XVI”.

44 La Revocación de Malinas de 1545 mantuvo la prohibición del otorgamiento de nuevas encomiendas y concedió derechos hereditarios por dos vidas. Zavala, La encomienda indiana, 80, 89. Sin embargo, en el caso del virreinato del Perú, el pacificador La Gasca tuvo que otorgar encomiendas para cumplir su misión. Rafael Loredo, Los repartos (Lima, 1958).

45 Salles, “Tributo y población”; y Estela Salles y Héctor Omar Noejovich, “Orígenes e incidencia de la mita toledana: un enfoque alternativo” (ponencia presentada en el 51 Congreso Internacional de Americanistas, Santiago, Chile, 2003).

46 Escobedo, El tributo, 139.

47 Ibídem, 140. 
[...] este testigo fue teniente gobernador de la ciudad de cuzco, y que sabe que el rey tenía allí indios y que nos los visitaron los oficiales ni los procuraban visitar como hacían los otros vecinos con los caciques, ni los granjeaban que pudieran dar oro y plata como los otros $[\ldots]^{48}$.

El obispo Berlanga le reclamó a Pizarro y el Marqués contestó en forma áspera, negando y contradiciendo las acusaciones del obispo ${ }^{49}$. La visita no llegó a producir los resultados esperados. Zavala señala que uno de los puntos para la sujeción a Su Majestad era estar bajo del Inca o señor del $\mathrm{Cuzco}^{50}$, mandato real que los conquistadores se resistían a cumplir, así como también la tasación de los tributos, la que solo se haría en 1549 con el licenciado Pedro de la Gasca ${ }^{51}$.

No obstante, se carece de información precisa de cuándo comienza la tributación efectiva, y solo resta la relación confeccionada en tiempos del marqués Cañete ${ }^{52}$, donde aparecen varios repartimientos de la corona, unos tomados de propietarios anteriores y otros sin ese antecedente ${ }^{53}$. Entre estos últimos aparece señalado el Collao (inferimos que se refiere a Chucuito) con una renta de 22.000 pesos.

\section{Tasaciones, población y ganadería}

\section{La tributación pretoledana}

No está muy claro cuándo se puso en práctica el cobro del tributo en la provincia de Chucuito, pero podemos asumir que se hizo efectivo después de la tasa de Cañete de 1559. Cole señala que la percepción de los tributos recién se habría llevado a cabo alrededor de $1560^{54}$.

48 Ibídem. El documento es la información secreta del obispo Berlanga de 1535 (Codoin, I. XX: 237292). Resaltado de los autores.

49 “[...] ha sido mal informado por españoles que deseaban congraciarse [...]”. Zavala, La encomienda, 849.

50 “Reitera que el Inga o Señor del Cuzco solo sirva a S. M.”. Ibídem, 847 y ss.

51 Rostworowski, Estructuras.

52 Escobedo, El tributo, 142.

53 El documento citado por el autor es inédito y se encuentra en la Biblioteca de la Academia Nacional de Historia (Madrid), Colección Muñoz.

54 Jeffrey Cole, The Potosí Mita, 1573-1700 Compulsory Indian Labor in the Andes (Stanford: UP, 1985), 2. Sin embargo, Díez de San Miguel, Visita, 207, señala: "Parece que por esta Real Audiencia, en el año de cincuenta y tres se dio tasa a los indios de la dicha provincia de dos mil pesos de plata ensayada y miel piezas de ropa, cumbi a auasca y mil hanegas de maís dos dos pesos y medio por cada hanega y mais doscientas hanegas de chuño puestas en el asiento de Potosí y cierta sementera de papa y ciertos indios arrieros para que los oficiales reales alquilar para Su Magestad y para guardar de ganados porque a la sazón se daban de tasa todas estas cosas a lo vecino comoo parece por latsa que está en esta visita y no he podido hallar claridad de lo que esta tasa valía hecho todo dinero porque se pagaba en la provincia de Los Charcas”. 
Por lo tanto, podríamos señalar que la corona recibió este repartimiento en lugar del de Cuzco, como fue su reclamo, y que la tributación efectiva empezó con el virrey Cañete. Este proceso fue contemporáneo al descubrimiento de las minas de Porco y Potosí, generando una estrecha relación entre la vida económica de la provincia de Chucuito y la región minera.

La tasa de Cañete representaba 18.000 pesos ensayados y 1.000 piezas de ropa; el circulante lo pagaban enviando 500 indios a las minas de Potosí, reuniendo de esa manera un total de 22.000 pesos ensayados, como lo indica la cédula que ordenó la visita:

[...] los indios del valle de Chucuito valen y rentan en cada un año veinte y dos mil pesos [...] dichos indios son muchos [...] y muy ricos [...] podrían pagar sin vejación ni molestia alguna más cantidad $[\ldots]^{55}$.

Esa apreciación se fundamentaba en la población ${ }^{56}$, cuya estructura por género y edad se desglosa en la Tabla 1.

Tabla 1

Población de Chucuito en 1567

\begin{tabular}{|l|c|c|c|}
\hline \multicolumn{1}{|c|}{ CLASE } & MASCULINA & FEMENINA & TOTAL \\
\hline Mayores de 16 años & 16.487 & 22.993 & 39.480 \\
\hline De 11 a 16 años & 1.827 & 1.828 & 3.655 \\
\hline Hasta 10 años & 9.788 & 9.789 & 19.577 \\
\hline TOTALES & 28.102 & 34.610 & 62.712 \\
\hline
\end{tabular}

Fuente: Noejovich, Los albores, 504.

En el sistema andino no solo trabajan los adultos, sino los viejos y los niños, de tal manera que podemos hablar de fuerza de trabajo y calcular su volumen (a la unidad la denominamos UFT), utilizando coeficientes para las distintas clases (Tabla 2) $)^{57}$.

55 Ibídem, 5.

56 Desde la visita de La Gasca en 1549, la población adulta había pasado de 32.208 a 39.470, creciendo a una modesta tasa de 1,4\% anual. Noejovich, Los albores, 504.

57 Para el procedimiento, Ibídem. Se trata de asignar coeficientes a cada clase: 1, para los adultos; 0,66, para los viejos y adolescentes entre 10 y 15 años; 0,33, para los niños entre 5 y 10; los menores de 5 años no son considerados. 
Tabla 2

Cálculo de la fuerza de trabajo, Chucuito 1567

\begin{tabular}{|l|c|c|c|}
\hline \multicolumn{1}{|c|}{ CLASE } & POBLACIÓN & COEFICIENTE & UFT \\
\hline $\begin{array}{l}\text { Casados, viejos viudos y solteros mayores } \\
\text { de 50 años }\end{array}$ & 5.575 & 0,66 & $3.679,50$ \\
\hline Casados, viudos y solteros de 16 a 50 años & 33.905 & 1,00 & $33.905,00$ \\
\hline Muchachos/as de 11 a 20 años & 3.655 & 0,66 & $2.412,30$ \\
\hline Muchachos/as menores de 11 años & 19.577 & 0,16 & $3.132,32$ \\
\hline TOTALES & 62.712 & & $43.129,12$ \\
\hline
\end{tabular}

Fuente: Noejovich, Los albores, 505.

Esta fuerza de trabajo, multiplicada por el número de jornadas ${ }^{58}$ de trabajo en el año, nos permite evaluar la capacidad laboral anual del grupo. En nuestro caso, suponiendo 260 jornadas por año y persona ${ }^{59}$, con su respectivo nivel de rendimiento y conforme los coeficientes señalados, podemos estimar la capacidad laboral anual del grupo en 11.213.571,12 jornadas o días-hombre.

El objeto de este desarrollo es evaluar la incidencia del tributo en tiempo de labor, dejando de lado cualquier cuestión monetaria y/o salarial. La estrategia para el pago del tributo está descrita en el testimonio de Martín Cari:

Preguntado qué orden tienen en la paga del tributo que ahora pagan a su Majestad y cuánto reparten a cada pueblo y cuánto cobran de cada indio y quién hace el repartimiento y lo recoge y cobra y si cobran tanto de un indio como de otro o si se pagan por haciendas tratos y caudales o qué orden es la que en esto se tiene dijo que la orden que se tiene y ha tenido de ocho o nueve años a esta parte es que en cada un año de toda la provincia sacan quinientos indios y los envían a trabajar a las minas de Potosí60.

La incidencia de esa estrategia de pago es visible en la Tabla 3, donde se calcula en jornadas o días-hombre el costo para la capacidad laboral anual del grupo.

58 El término jornada lo utilizamos en el sentido de un día de trabajo, sin ningún horario.

59 Se suponen cinco jornadas por semana. Somos conscientes de que es un estimado bajo para la capacidad laboral anual del grupo, pero suficiente para desarrollar nuestras hipótesis sobre la incidencia del tributo en la población indígena. En efecto, si aumentáramos a 300 días, por ejemplo, la incidencia sería aún menor.

60 Díez, Visita, 19. Resaltado de los autores. 


\section{Tabla 3}

\section{Costo del tributo en jornadas en Chucuito (1567), según la estrategia indígena}

\begin{tabular}{|l|c|}
\hline \multicolumn{1}{|c|}{ CONCEPTO } & JORNADAS \\
\hline 500 Indios que van a trabajar a las minas & 130.000 días-hombre \\
\hline 1.000 piezas de ropa & 44.550 días-hombre $^{61}$ \\
\hline Transporte de ida & 56.500 días-hombre $^{62}$ \\
\hline Total de jornadas empleadas en el tributo & 234.550 días-hombre \\
\hline
\end{tabular}

Fuente: A partir de Noejovich, Los albores, 166, y Díez, Visita.

Comparado con la capacidad laboral anual (11.213.571,12 días-hombre), el costo del tributo significa 2,09\% de aquella. Si argumentamos que también hay que adicionar a la familia y el transporte de vuelta (que no siempre ocurría, porque los indios se quedaban en Potosí) podríamos duplicar esa incidencia, pero la presión tributaria resultaría igualmente baja (4\%).

La nueva tasación como consecuencia de la visita será de 20.000 pesos y 1.600 piezas de ropa ${ }^{63}$.

\section{La estructura agrícola-ganadera}

Para aproximarnos, la Tabla 4 muestra cuántos indios mitmakuna estaban en los valles alejados del altiplano para proveer a Chucuito de maíz, coca, quinua y similares:

61 El cálculo es el siguiente:

Jornadas insumidas para hechura de ropa

\begin{tabular}{|l|r|r|}
\hline \multicolumn{1}{|c|}{ Testimonio } & Piezas & \multicolumn{1}{c|}{ Días } \\
\hline Martín Cari & 1,50 & 45 \\
\hline Bernardino Gallego & 1,00 & 50 \\
\hline Melchior de Alarcón & 1,00 & 30 \\
\hline Fray Tomas Castillo & 1,00 & 60 \\
\hline Fray Francisco Loyola & 1,00 & 60 \\
\hline Total & 5,50 & 245 \\
\hline Promedio & & 44,55 \\
\hline
\end{tabular}

62 Ibídem, 19.

63 Ibídem, 272. 


\section{Tabla 4}

\section{Indios mitmakunas en los valles}

\begin{tabular}{|l|c|}
\hline \multicolumn{1}{|c|}{ ZONA } & TRIBUTARIOS \\
\hline Moquegua & 303 \\
\hline Sama & 334 \\
\hline Hichura & 11 \\
\hline Larecaja & 70 \\
\hline Chicanoma & 22 \\
\hline TOTAL & $\mathbf{7 4 0}$ \\
\hline \hline
\end{tabular}

Fuente: Salles, Tributo, 52.

Comparando con el total de tributarios de la Tabla 2, que es de 33.905 entre 16 y 50 años, obtenemos una aproximación. Pero, más importante:

[La] Provisión para la administración del ganado de la comunidad [...] que los indios de esta provincia tienen cuarenta y tantas mil cabezas de ganado de la tierra de esta comunidad y otra cierta cantidad de ganado de Castilla ${ }^{64}$.

Mediante esta provisión, el licenciado Lope García de Castro, presidente de la Audiencia de Lima, indica:

[... elijo y nombro de todo el dicho ganado de la comunidad de la dicha provincia de Chucuito a don Martín Cari y a don Martín Cusi [... $]^{65}$.

El valor de ese ganado puede estimarse a razón de 6,5 pesos ensayados por cabeza de ganado de la tierra y 3,25 pesos ensayados por cabeza de ganado de Castilla ${ }^{66}$. Grosso modo, esto arroja unos 300.000 pesos ensayados, cantidad muy superior al tributo. Sin embargo, esa cifra parece baja, como veremos más adelante.

\section{Los negocios de los frailes dominicos}

Al respecto, hay dos casos ilustrativos: 1. El “concierto” realizado por los indios con los frailes, a fin de proporcionarles ganados para su sustento ${ }^{67}$. Los indígenas dieron a los frailes un número determinado de cabezas de ganado para que se alimentaran de su “multiplico”. La tasa de Cañete fijaba la prestación en dos carneros por fraile y por

\footnotetext{
64 Ibídem, 373.

65 Ibídem, 274.

66 Héctor Omar Noejovich, “La economía andina en el entorno de la conquista española” (tesis de maestría, Pontificia Universidad Católica del Perú, 1983), 52.

67 Para un detalle más amplio de este caso véase Noejovich, Los albores, 168 y ss.
} 
mes; conforme con el parecer del visitador, las cifras del multiplico corresponden a un período de cuatro años, lapso que medió entre la concertación y la visita.

Según los datos ${ }^{68}$, puede establecerse la siguiente relación:

$$
\begin{gathered}
\text { Reproducción neta }=\text { hacienda final }- \text { hacienda inicial }+ \text { consumo estimado }= \\
6.357-2.034=5.517 \text { cabezas de ganado }
\end{gathered}
$$

Asumiendo que solo se consumieron ejemplares machos ${ }^{69}$, la reproducción neta se desglosa en 2,635 machos y 2,946 hembras. Seguramente los religiosos sacrificaron y/o vendieron más cabezas de aquellas que les correspondían. En esas circunstancias, el consumo estimado aumentaría. Sin embargo, es válida la hipótesis del razonamiento efectuado por los kurakuna para realizar el concierto.

En su declaración, Martin Cari enumera la estructura de la hacienda utilizada como base para ese concierto, cuyo resultado encontró el visitador ${ }^{70}$. El cálculo, en función de un período de cuatro años, corresponde al tomar ambos extremos, pero no parece razonable asumir que los indígenas hubiesen pensado en ese lapso, sino en un período asociado con la cría y el engorde, de dos a tres años. Las tasas de reproducción anual del ganado, según esas alternativas, son: para dos años, 37,0 \%; para tres años, 32,2 \%; para cuatro años, 28,9 \%.

Como la cantidad de machos entregados inicialmente superaba las necesidades de reproducción (p. e. 100 machos y 150 hembras), suponemos que el exceso estaba destinado a cubrir las necesidades de los frailes en los dos primeros años. Bajo cualquier supuesto de tasas de reproducción, el consumo estimado resulta inferior a la reproducción neta de los machos, cuya cantidad se incrementó entre el concierto y la visita, aun con las exacciones y abusos por parte de los frailes.

Sintetizando, los señores de Chucuito, autores de la concertación, presuponían que los frailes consumieran solo parte de los machos reproducidos, manteniendo el potencial de la hacienda. Esto muestra un cabal conocimiento de la ganadería, que fue aceptado por los españoles, como indica la "Provisión para nombrar administradores del ganado" citada más arriba.

2. Los “negocios” de Formicedo ${ }^{71}$. Este fraile fue nombrado vicario de Chucuito por el obispo del Cuzco, en $1552^{72}$, y es un ejemplo representativo del negocio ganadero

68 Ibídem, 505.

69 La cría de ganado para engorde se realiza castrando a los machos y reservando algunos como reproductores; las hembras no se consumen mientras están destinadas a la procreación, toda vez que la disponibilidad de vientres es el factor determinante para la reproducción de la hacienda.

70 Díez, Visita, 16.

71 Esta sección está tomada e inspirada en Noejovich, "Las visitas".

72 Meiklejohn, La iglesia, 49. 
de los dominicos, dada la envergadura de sus tratos. El negocio comienza con un "parlamento que hizo a los indios" en los siguientes términos, según los testimonios de estos:

[...] que habra onze años poco mas o menos ${ }^{73}$ estando en esta doctrina e pueblo el dicho fray Agustin de Formicedo junto un dia a todos los caçiques y principales de este pueblo y les dixo que ya savian que el ganado que tenian de la tierra de la comunidad era del inga y del sol e que seria bien que lo bendiesen e comprasen ganado de Castilla y hiciesen un obraje para que de la lana hiciesen fraçadas y paños y sayas y bendiesen para pagar su tasa porque era peligroso tener el dicho ganado que se lo tomarian en saviendo que hera del inga y del sol quielquiera Justiçia de Su Magestad porque era suyo y no de los indios por ser del sol y del inga y les mando lo juntasen todo luego y aunque los dichos caciques y principales le resistieron para que no se lo vendiesen como despues se bendio diziendole que como lo havian de vender no teniendo otro ganado de que sacar lana para hazer la ropa que la tasa les manda dar a Su Magestad y porque Don Felipe Ticona principal del ayllo lo quiso defender e fue el que mas replico lo prendio y lo tubo preso en un buio tres dias y le amenaço que lo avia de açotar sino hacia que se traxese el dicho ganado como honbre que tenia la guada y la quenta a su cargo y a todos los demas caçiques y principales le amenaço ansi mesmo que los avia de prender y açotar sino lo hacían traer y ellos de miedo traxeron el dicho ganado al pueblo de Batalla sujeto a este pueblo que esta a una legua del mas de mill docientas caveças del dicho ganado de los quales escogo el mejor y lo vendio a un vicario de la ciudad de la Paz que se llama Pedro Marquez ${ }^{74}$.

Para realizar la operación el fraile utilizó dos argumentos: primero, que el ganado no era de los indios y estos corrían el riesgo de que se lo incautaran, persuadiéndolos de las “bondades de establecer un obraje con lana de Castilla”. El otro era la compulsión a través de la amenaza corporal. En este contexto, los precios, que mencionaremos luego en las valorizaciones, son fruto de una posición de fuerza y no el resultado de una negociación de mercado ${ }^{75}$. Por otro lado, el argumento de los indios sobre la falta de la lana para la tasa de Su Magestad era correcto ${ }^{76}$, y la transformación en obrajes

73 Aproximadamente en 1561, nueve años después de que el fraile fuera nombrado vicario y seis años antes de la visita de Garcí Díez.

74 Franklin Pease, "Nota sobre los visitadores de Chucuito en 1574”, Historia y Cultura (Lima), 4 (1970): 22.

75 Detalle importante en las transacciones coloniales, en el cual, lamentablemente, la historiografía económica no repara adecuadamente, que en muchos casos tiende a interpretarlos como resultados de la ley de la oferta y la demanda.

76 Recordemos que, según la tasación de Garcí Díez de San Miguel en Visita, 271, los indios de Chucuito debían entregar 1.600 piezas de ropa. Estas eran confeccionadas con lana de la tierra. Por otra parte, los animales de la tierra servían también para carga, no así las ovejas de Castilla. 
que proponía serviría para generar el dinero de la tasa ${ }^{77}$. En resumen, esta operación puede cuantificarse como queda establecido en la Tabla 5.

Tabla 5

El ganado y subproductos tomados a los indios

\begin{tabular}{|l|l|r|l|}
\hline UNIDADES & \multicolumn{1}{|c|}{ ESPECIE } & VALOR & \multicolumn{1}{c|}{ ORIGEN } \\
\hline 1.099 & Cabezas de la tierra & 4.525 & Comunidad \\
\hline 69 & Cabezas de la tierra & 466 & Particulares \\
\hline 114 & Cabezas en charque $^{78}$ & 57 & Comunidad \\
\hline 11 & Arrobas de lana & 115 & Comunidad y particulares \\
\hline Sin datos & Ovejeros & s. d. & Particulares \\
\hline 1.282 & Cabezas & 5.163 & TOTAL \\
\hline
\end{tabular}

Fuente: Pease, “Nota”, 19 y 22.

Los indios reclamaron por los precios, pero además surgió el problema del destino del dinero, como señalaron los testigos:

[... ] y que la plata en que se vendio el ganado al dicho vicario la cobro el dicho fray Agustin sin que entrase en poder de los dichos caçiques e indios no save lo que monto ni si los vendio al dicho precio mas de quel les dixo lo havia vendido e concertado ansi como tienen dicho e que la plata que el dicho fray Agustin de Formacedo cobro del dicho vicario la truxo junto a la Laguna asta casa y mando a los indios que la trayan que la traxesen por el camino real y la llevo donde a pocos dias al Cuzco y la metio según declaro con Felipe Cocapaca testigo en un aposento en el monasterio de Santo Domingo de la dicha ciudad dvaxo de su cama e que compro ochoçientas setenta y cinco obejas de Castilla y treinta carneros para padres y las obexas truxeron doçientas y treinta e nueve corderos de parición de un mes poco mas o menos [...] a este dicho pueblo les tomo quatrocientas y cien corderos $[\ldots]^{79}$.

Es evidente que el "negocio" del fraile fue sustituir el ganado de la tierra por ganado de Castilla, comprado a un precio menor. El resultado de la operación, con las cifras de que disponemos, se estima en la Tabla 6.

77 Esta, sin embargo, estaba cubierta con el envío de indios a Potosí, conforme se señaló anteriormente.

78 Corresponden a los animales muertos, así como la arroba, que también fueron exigidos por Fray Formicedo.

79 Pease, “Nota”, 22. 
Tabla 6

Balance de la operación de Formicedo

\begin{tabular}{|c|c|l|c|}
\hline \multicolumn{2}{|c|}{ TOMADOALOS INDIOS } & \multicolumn{2}{c|}{ RECIBIDOACAMBIO } \\
\hline \multicolumn{1}{|c|}{ Ganado de la tierra } & Valor $^{80}$ & \multicolumn{1}{|c|}{ Ganado de castilla } & Valor $^{81}$ \\
\hline $\begin{array}{l}1.282 \text { cabezas } \\
\text { (incluidas las faenadas) }\end{array}$ & 5.163 & $\begin{array}{l}1.144 \text { cabezas compradas } \\
\text { (incluidas la parición) }\end{array}$ & 2.263 \\
\hline & & Menos: 500 cabezas retenidas & 1.150 \\
\hline & & NETO RECIBIDO POR LOS INDIOS & 1.113 \\
\hline & Beneficio de Formicedo & 4.050 \\
\hline TOTAL & 5,163 & TOTAL & 5.163 \\
\hline
\end{tabular}

Fuente: Pease, “Nota”, 19 y 22.

Esta cifra era elevada, teniendo en cuenta que la tasa de Cañete, señalada anteriormente, era de 18.000 pesos ensayados; el negocio de Formicedo, fundamentalmente ganadero, representaba para él un beneficio del orden del 22,5\% de la tasación.

\section{Evaluación de recursos y pareceres en la visita de $1574^{82}$}

Los visitadores percibieron, como antes lo hicieron los frailes, la capacidad que tenían los habitantes de la provincia de Chucuito para producir ropa y realizar arrieraje:

Por la mayor parte tiene todos los indios que les es de mucho util y provecho ansi por la lana que tienen, para hacer su ropa como por los carneros de carga $[\ldots]^{83}$.

Por consiguiente, propusieron:

[...] mandar a hazer por quenta de su magestad y ayuda a sus reales tributos en cada un año siete mill pieças de ropa de abasca $[\ldots]^{84}$.

Esto representaría unos 28.000 pesos ensayados ${ }^{85}$. Pero no solamente proponían eso, también sacar 4.000 carneros grandes y otros tantos pequeños, y venderlos por cuenta de Su Majestad, obteniendo unos 24.000 pesos. Esta evaluación fue realizada con el cálculo de la parición y siempre referida al “ganado de la comunidad”.

\footnotetext{
$80 \quad$ Ibídem, 19 y 22.

81 Según Noejovich, “La economía”, 52.

82 Esta sección está tomada e inspirada en Noejovich, “Las visitas”.

83 Pease, “Nota”, 41.

84 Ibídem, 43.

85 Recordemos que hasta ese momento la tasa era solamente de 1.600 piezas.
} 
Tabla 7

\section{Comparación de las cifras de población y relevamiento de los recursos. Visita secreta de 1574}

\begin{tabular}{|l|r|}
\hline \multicolumn{1}{|c|}{ POBLACIÓN } & CANTIDADES \\
\hline Aymaraes tributarios & 12.271 \\
\hline Uros tributarios & 3.198 \\
\hline Subtotal de tributarios & 15.459 \\
\hline Chucuito-total & 66.900 \\
\hline Infieles & 15.591 \\
\hline Mitmakunas tributarios & 676 \\
\hline Sama y Moquegua-total & 3.415 \\
\hline Repartimiento-tributarios & 16.135 \\
\hline Repartimiento-total & 70.316 \\
\hline Chucuito-total/tributarios & 4,33 \\
\hline Sama y Moquegua-total/tributarios & 5,05 \\
\hline Repartimiento-total/tributarios & 4,37 \\
\hline \multicolumn{1}{|c|}{ RECURSOS } & 60.341 \\
\hline Ganado de comunidad & 99.356 \\
\hline Ganado de particulares & 159.697 \\
\hline Total de ganado & 7.000 \\
\hline Chácaras-topos & \\
\hline
\end{tabular}

Fuente: Noejovich, “Las visitas”, 780.

Siempre en el contexto de una propuesta de tributación con menor vejación para los indios, propusieron el envío de 1.000 a 1.200 hombres a trabajar a las minas ${ }^{87}$.

[...] y tributen a su magestad el tributo que a Vuestra excelencia le pareçiere puedan buenamente pagar de manera que les quede con que sustentar y comer al tiempo questubieren de la dhas minas y el sobre alguna plata $[\ldots]^{88}$.

\footnotetext{
86 Medida variable, según el tipo de tierra y cultivo. Podemos estimarla entre 0,36 y 2 hectáreas. Noejovich, Los albores, 179 y182.

87 La propuesta es de 1.000 indios con un adicional de 100 a 200, para "que los mill esten siempre enteros". Pease, "Nota”, 43.

88 Ibídem, 42.
} 
Detrás de esa aparente bondad en realidad se estaba cuadruplicando la exacción tributaria. Los mismos visitadores resumen en el documento las posibilidades de tributación (Tabla 8).

Tabla 8

Propuesta de los visitadores

\begin{tabular}{|l|c|}
\hline \multicolumn{1}{|c|}{ CONCEPTO } & PESOS ENSAYADOS \\
\hline 7.000 piezas de ropa & 28.000 \\
\hline Venta de ganado de la comunidad & 24.000 \\
\hline 1.000 indios tributando 40 pesos $^{89}$ & 40.000 \\
\hline TOTAL & 92.000 \\
\hline
\end{tabular}

Fuente: Noejovich, “Las visitas, 781.

La tasación final, su distribución y la cuestión de los indios ricos

Finalmente, la tasación quedó fijada en 80.000 pesos ensayados (las diferencias en las Tablas 9 y 10 son irrelevantes para nuestra exposición).

Tabla 9

Tasa de la visita general de Toledo

\begin{tabular}{|l|r|c|}
\hline FORMA DE TRIBUTACIÓN & \multicolumn{2}{|c|}{ PESOS ENSAYADOS } \\
\hline Mitayos en Potosí & Parcial & Total \\
\hline 1.600 aymaraes y mitimaes & 28.800 & \\
\hline 400 uros & 6.400 & \\
\hline 200 aymaraes & 3.200 & 36.400 \\
\hline Demás indios del repartimiento & & \\
\hline 10.967 aymaraes y mitimaes & 32.291 & \\
\hline 569 uros & 1.707 & \\
\hline $\begin{array}{l}\text { 1.922 piezas de ropa } \\
\text { (las arriba indicadas) }\end{array}$ & 3.844 & \\
\hline 2.968 uros & 4.526 & \\
\hline 445 piezas de ropa (2.968 uros) & 890 & 43.258 \\
\hline TOTAL & & $\mathbf{7 9 . 6 5 8}$ \\
\hline
\end{tabular}

Fuente: Noejovich, “Las visitas”, 782.

89 Los 40 pesos surgen de dividir la tasa de Garcí Diez, de 20.000 pesos ensayados, entre los 500 indios que iban a Potosí anualmente para pagar la tasa de Cañete. 
En cuanto a la distribución de la tasa, tenemos la Tabla 10.

Tabla 10

Distribución de la tasa de Toledo
(Pesos ensayados y marcados)

\begin{tabular}{|l|c|c|}
\hline \multicolumn{1}{|c|}{ Destino } & Importe parcial & Importe total \\
\hline Sacerdotes & & 20.065 \\
\hline Hospitales & & 2.050 \\
\hline Corregidores & & 3.000 \\
\hline Defensor y protector & & 600 \\
\hline Caciques & & 3.880 \\
\hline Su Majestad & & 50.400 \\
\hline En plata & 45.666 & \\
\hline En ropa & 4.734 & \\
\hline TOTAL & $\mathbf{7 9 . 9 9 5}$ & \\
\hline
\end{tabular}

Fuente: Salles, “Cuestiones”, 139.

Esta distribución generó la protesta de los indios, lo que indica la existencia de “indios ricos”. Nuevamente, Toledo comisionó a Pedro Gutiérrez Flores, quien confeccionó un "Padrón de los mil indios ricos de la Provincia de Chucuito" 90 . El objeto de la misma era distribuir 5.000 pesos ensayados y media pieza de ropa entre 1.000 indios considerados ricos por tener 50 cabezas o más, disminuyendo la carga sobre el resto. Esa distribución se realizó más o menos proporcionalmente al número de cabezas que tenía cada uno, pero, como puede apreciarse en la Figura 3, el universo era bien disperso, pero concentrado en las unidades menores, como lo señalan los indicadores estadísticos. El total de la hacienda de esos 1.000 indios era de $137.105^{91}$.

\section{Evaluación y conclusiones finales}

1. Para el análisis de la proporción entre las labores agrícolas y las ganaderas (incluyendo las textiles), tomaremos como indicador la relación entre las poblaciones de Sama y Moquegua (3.415) con el total del repartimiento (70.316) ${ }^{92}$, aproximadamente un $5 \%$. Puede alegarse una incidencia mayor si se considera el caso de Larecaja y el

90 Díez, Visita, 301 y ss.

91 Pero quedaron empadronados también 376 indios ricos, con un total de 23.016 cabezas que no fueron tasadas.

92 Véase Tabla 7. 


\section{Figura 3}

\section{Existencias de ganados de los 1.000 indios ricos. Análisis de su distribución}

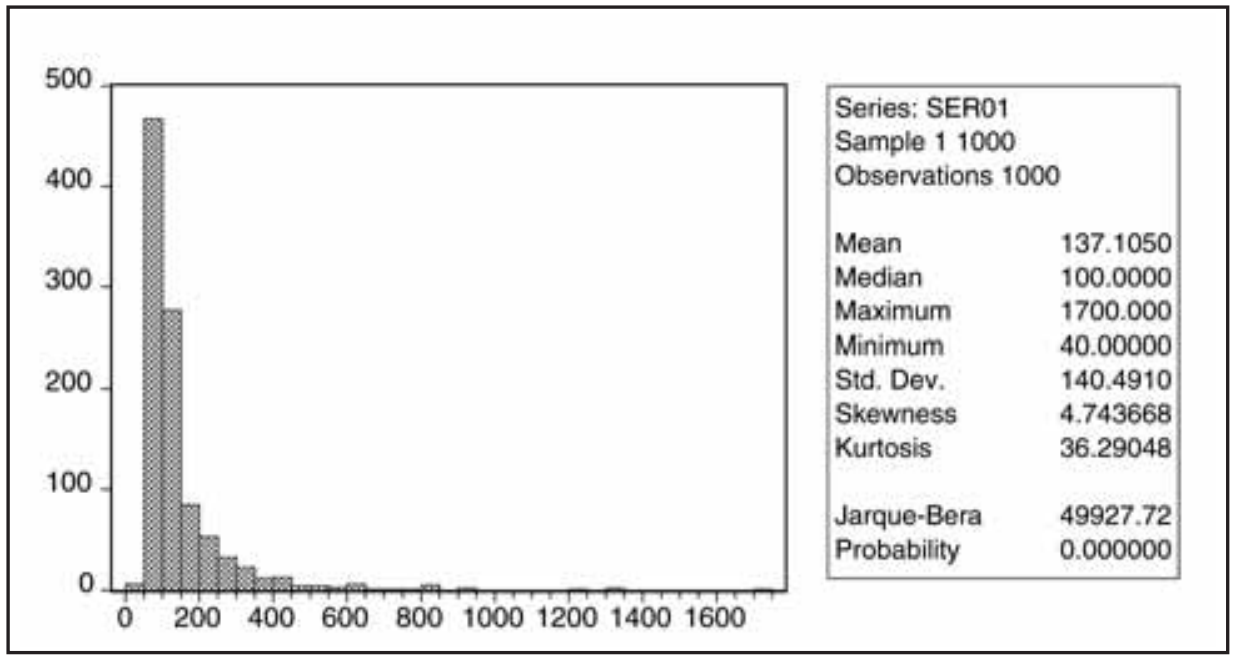

Fuente: Elaboración del autor.

cultivo de papa alrededor del Titicaca, pero es evidente que el “campesinado” era escaso y no precisamente generador de "renta”. Su actividad era de subsistencia.

2. Hay discrepancias sobre el número de cabezas, las tenencias individuales y las comunitarias. Si los supuestos ricos tenían 160.121 cabezas (137.105 + 23.016), ¿cómo inventariaron los visitadores 159.627 entre particulares y comunidad? Aparentemente hay confusión de los visitadores en cuanto a las categorías "comunidad” y "particulares”. Tomando en cuenta los valores calculados (unos seis pesos ensayados por cabeza) el valor del "stock ganadero" a la usanza española puede calcularse en alrededor de 1.000.000 de pesos ensayados. Esta es una cifra enorme, que incluso superaba muchos envíos de plata para la corona.

3. Tomando como base la Tabla 5, donde Formicedo recibió 114 cabezas muertas en forma de charque y 11 arrobas de lana ${ }^{93}$, y sobre la base de una relación de 0,1 arrobas por animal, equivalentes a 2,5 libras, suponiendo que se requieran cinco libras por pieza de ropa, esto sería la esquila de dos cabezas de ganado. Por lo tanto, la capacidad de generación de tejido puede estimarse en 80.000 piezas de ropa sobre la base de una esquila anual de toda la hacienda94. Con los “precios" de los visitadores, esa "producción textil” a partir de las existencias ganaderas representaría unos 320.000 pesos ensayados, suma también considerable.

93 Una arroba son 25 libras.

94 En general, a la llama no se la esquila, al menos con esa frecuencia, por tratarse de una animal de carga. 
4. Con referencia a la utilización de la mano de obra, habíamos estimado la fuerza de trabajo en 11.213.571,12 UFT (Tabla 2); los mitayos a Potosí (2.200) representaban 8.660 personas, según la Tabla 7, lo que era un “sacrificio” de 1.548.500 UFT. Por otro lado, suponiendo la producción de las 80.000 piezas, estas insumirían 3.563.200 $\mathrm{UFT}^{95}$. En total, sería solamente la mitad de su capacidad de fuerza de trabajo.

5. Sin desconocer la relatividad de todas estas cifras y los cálculos derivados de ellas, parece ser que todo conduce a afirmar que la supuesta riqueza estaba en la "administración” de la hacienda y que la renta que generó el repartimiento para la corona no fue tan sufrida como en las encomiendas sustentadas sobre bases agrícolas. El pastoreo y el cuidado de la hacienda ganadera los protegió de la explotación encomendera.

6. Deberíamos observar en futuras investigaciones el comportamiento de este espacio geográfico en la larga duración y de esta manera establecer comparaciones en el tiempo.

\section{Bibliografía}

\section{Fuentes primarias}

Díez de San Miguel, Garcí. Visita a la provincia de Chucuito de 1567, ed. Waldemar Espinoza Soriano. [1567]; Lima: Casa de la Cultura, 1964.

Morales, Alfonso, ed. Repartimiento de tierra por el Inca Huayna Capac: testimonio de un documento de 1556. [1556]; Cochabamba, Perú: Universidad Mayor de San Simón, 1977.

Porras Barrenechea, Raúl. Cedulario indiano. Lima, 1944.

\section{Fuentes secundarias}

Antunez de Mayolo, Santiago, comp. Geografía del Perú. Anuario geográfico departamental. Lima: Fondo Editorial de la Sociedad Geográfica, 1990.

Burga, Manuel. De la encomienda a la hacienda capitalista. Lima: IEP, 1976.

Cole, Jeffrey. The Potosí Mita, 1573-1700 Compulsory Indian Labor in the Andes. Stanford: UP, 1985.

Deustua Jameson, Luis. Organización de una hacienda ganadera en Puno. Informe 28. Lima: Ministerio de Agricultura; Coama, 1972.

95 Estimamos en 44,54 d/h la producción de una pieza de ropa. Noejovich, “La economía”, 73. 
Dollfus, Olivier. El reto del espacio andino. Lima: IEP, 1981.

Escobedo, Ronald. El tributo indígena en el Perú (Siglos XVI-XVIII). Pamplona: Universidad de Navarra, 1979.

Góngora, Mario. Estancieros y encomenderos. Santiago de Chile, 1970. . El origen de los inquilinos de Chile central. Santiago de Chile: Icira, 1974.

Hampe, Teodoro. "La encomienda en el siglo XVI: estudio socioeconómico de una institución colonial”. Memoria inédita. Lima: Pontificia Universidad Católica del Perú, 1983.

Hyslop, John. “El área Lupaqa bajo el dominio incaico”, Histórica (Lima), 3, núm. 1.

Loredo, Rafael. Los repartos. Lima, 1958.

Meiklejohn, Norman. La Iglesia y los Lupaqas. Lima, 1988.

Murra, John V. El mundo andino. Población, medio ambiente y economía. Lima: IEP; Pontificia Universidad Católica del Perú, 2002.

Noejovich, Héctor Omar. "La economía andina en el entorno de la conquista española”. Tesis de maestría, Pontificia Universidad Católica del Perú, 1983.

. "El régimen de bienes en la América precolombina y el hecho colonial”. CISEPA (Lima), 107 (1992).

. Los albores de la economía americana. Lima: Pontificia Universidad Católica del Perú, 1996.

. "Las visitas de Chucuito en el siglo XVI: en torno a la visita secreta". En El hombre y los Andes. Ensayos en honor a Franklin Pease G-Y. Lima: Pontificia Universidad Católica del Perú; Instituto Francés de Estudios Andinos; Banco de Crédito del Perú, 2002.

- "Indios en México y Perú”. En Construir la Historia. Homenaje a Ruggiero Romano. Coord. Alejandro Tortolero (México, 2002).

Pease, Franklin. “Nota sobre los visitadores de Chucuito en 1574”. Historia y Cultura (Lima), 4 (1970).

. "Relaciones entre los grupos étnicos de la sierra del sur y la costa: continuidades y discontinuidades". En El hombre y su ambiente en los Andes centrales. Ethnological Studies, núm. 10, eds. Luis Millones y Hyrosayu Tomoeda. Osaka, 1982. 
Romano, Ruggiero. Consideraciones. Lima: Fomciencias, 1992.

Rostworowski, María. Estructuras andinas de poder. Lima: IEP, 1983.

Saignes, Thierry. Algunas hipótesis acerca del control aymara de los valles de Larecaja (La Paz, 1975).

. "Les ethnies dans les vallées de Larecaja: de la filiation a la résidence", Annales (París), 33, núm. 5/6 (1975).

. "Les Lupacas dans les vallées orientales des Andes: trajets spatiaux et repères démographiques: XVI-XVII siècles”, Mélanges de la Casa de Vélasquez (París), 17 (1981): 147-182.

Salles, Estela Cristina. "Martín Cari-Martín Cuxi. Dos estrategias disyuntivas de supervivencia frente al tributo". Actas de las V Jornadas Interescuelas de Departamentos de Historia y I Jornadas Rioplatenses de Historia, Montevideo, 1995.

. "La evolución tributaria de Chucuíto, sur del Perú, siglo XVI”. Journal of Iberian and Latin American Studies (Melbourne, Australia), (julio 2000).

. “Tributo y población en una encomienda real. Chucuito 1549-1574”. Tesis, Universidad Nacional de Luján, Argentina, 2000.

. "Cuestiones sobre Chucuito en el siglo XVI. Las exacciones de la Iglesia”. En América bajo los Austrias, economía, cultura y sociedad, ed. Héctor Omar Noejovich. Lima: Pontificia Universidad Católica del Perú, 2001.

Salles, Estela y Héctor Noejovich. "Orígenes e incidencia de la mita toledana: un enfoque alternativo”. Ponencia presentada en el 51 Congreso Internacional de Americanistas. Santiago, Chile, 2003.

Wachtel, Nathan. "Les mitmas de la vallée de Cochabamba: la politique de colonisation de Huayna Capac”. Journal de las Société des Américanistes (París), 67 (1982).

Zavala, Silvio. El servicio personal de los indios en el Perú, 1 t. México: El Colegio de México, 1978. . La encomienda indiana. México: Porrúa, 1992.

Fecha de recepción: 2 de junio de 2004.

Fecha de aceptación: 24 de agosto de 2004. 